\title{
Supporting Information: Systematic Correlation Matrix Evaluation (SCoMaE) - A bottom-up, natural science-based approach to identify Indicators
}

Nadine Mengis ${ }^{1,2}$, David P. Keller ${ }^{2}$, and Andreas Oschlies ${ }^{2,3}$

${ }^{1}$ Concordia University, Montreal, QC, Canada

${ }^{2}$ Helmholtz Center for Ocean Research Kiel (GEOMAR), Düsternbrooker Weg 20, 24105 Kiel, Germany

${ }^{3}$ Kiel University, D-24098 Kiel, Germany

Correspondence to: N. Mengis, Concordia University, Montreal, QC, Canada, nadine.mengis@concordia.ca 


\section{Indicators for the future scenarios}

\subsection{Indicators for the RCP4.5 scenario}

In the RCP4.5 scenario, carbon emissions continue to rise. In addition, the area of historical land use changes is reduced and forest is grown on the newly freed areas. Some of imposed parameter perturbations are designed to scale the sensitivity of vegetation and soil to temperature and carbon, we therefore expect these to be sensitive for this scenario.

The evaluation of the correlation matrix for the RCP4.5 scenario (Figure S1), resulted in 'oceanic evaporation' (F_evapO), which is significantly correlated with 34 other variables, being chosen as the first indicator. The second indicator for the RCP4.5 scenario is 'precipitation over land' (F_precipL), which is significantly correlated to 'vegetation net primary productivity' (L_vegnpp), 'terrestrial evapotranspiration' (F_evapL), 'surface albedo on land' (A_albsurL) and 'net upward longwave radiation' (F_uplwr) (Figure S1). The next indicators are 'ocean phytoplankton' (O_phyt), which is clustered with 'ocean surface nitrate' (O_no3sur) and 'ocean surface phosphate' (O_po4sur); and 'ocean oxygen' (O_o2), which is clustered with 'ocean surface alkalinity' (O_alksur). The last two indicators, 'top of atmosphere outgoing longwave radiation' (F_outlwr) and 'maximum meridional overturning' (O_motmax), are needed to assess the entire system, but are not significantly correlated to any remaining variables.

These changes in the selected indicators (relative to the historical indicators) can be explained when visually comparing the correlation matrices of the historical and the RCP4.5 scenarios (Figures 3 and S1). It is most obvious for two variables, namely the 'air to sea carbon flux' (F_carba2o) and the 'air to land carbon flux' (F_carba2l), because the sign of correlation towards their indicator and correspondingly to other related variables, changes. These changes are driven by the land forcing of the different scenarios as well as the carbon storage capacities of the reservoirs. In the historical scenario, the land use changes, which are prescribed from the CMIP5 forcing and based on historical data, dominate the land carbon flux, resulting in a net carbon flux from the land to the atmosphere, although the increasing atmospheric $\mathrm{CO}_{2}$ concentrations would naturally act to fertilize the plants and increase the carbon uptake on land, this is in agreement with observed carbon fluxes (Le Quere et al., 2015). The ocean in the UVic ESCM acts as a net carbon sink in the historical scenario, taking up the carbon emissions from fossil fuel combustion as well as from anthropogenic land use changes, which is again in agreement with observations (Le Quere et al., 2015)

In the RCP4.5 scenario, anthropogenic land use is prescribed to be strongly reduced, due to an assumed increase in the efficiency of crop production (Thomson et al., 2011). Hence the area of naturally occurring forest and grass lands increase, and a higher amount of carbon is taken up by the land due to the $\mathrm{CO}_{2}$ fertilization effect. Later in the simulations between 2050 and 2100, the land as well as the upper ocean carbon uptake potential are saturated, the land reservoir turns into a carbon source for the atmosphere and the ocean carbon uptake starts to decrease from about 2050 onward. Such a reaction is found in CMIP5 models as well, however the timing of this sink to source transition varies strongly among the models (Eby et al., 2013). This change in behavior, from forced to more natural behavior in the terrestrial carbon reservoir, and the transition from sink to source in the terrestrial reservoir, cause the correlations to change their signs. 
Correlations of changes between 2005 and 2100

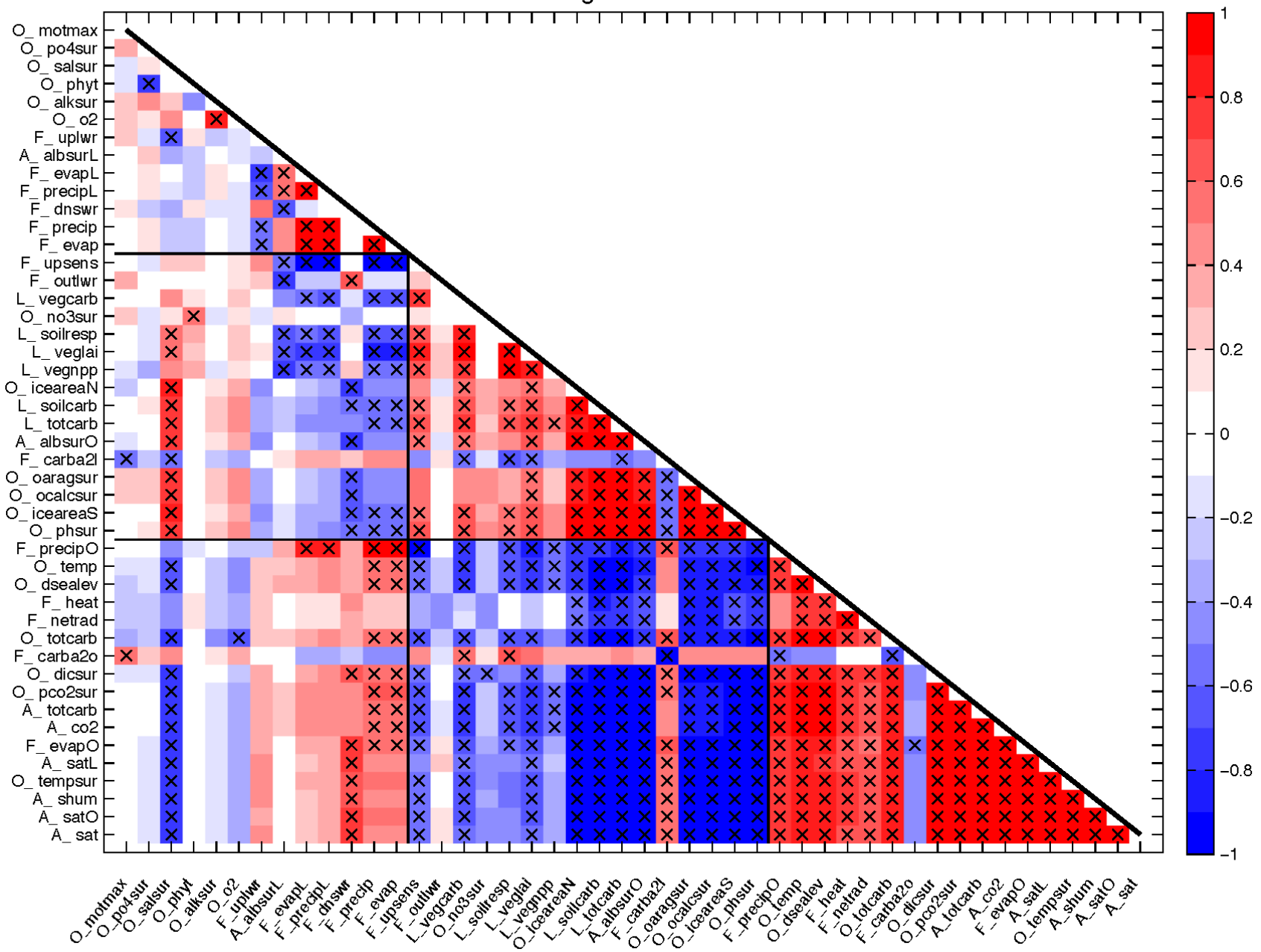

Number of significant correlations for the RCP4.5 scenario

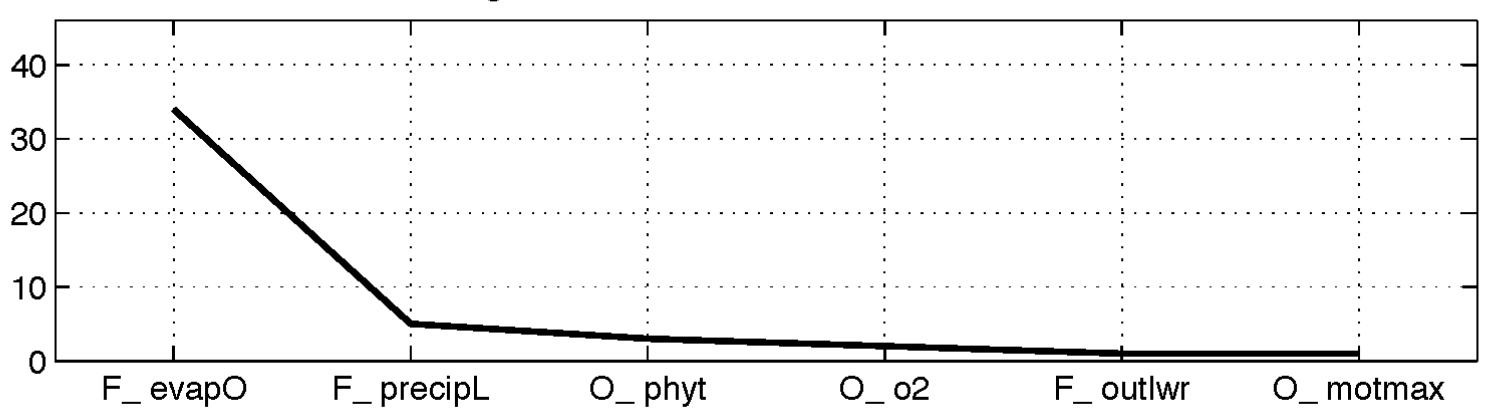

Figure S1. Same as Figure 3 in the main article, for the RCP4.5 scenario. 


\subsection{Indicators for the RCP8.5 scenario}

For the RCP8.5 scenario we impose a high $\mathrm{CO}_{2}$ emission scenario (RCP8.5) and further increasing land use changes. Some of the perturbed parameters react directly sensitive to $\mathrm{CO}_{2}$ or are temperature sensitive, and therefore will show a strong reaction to the additional forcing.

5 The first indicator for the RCP8.5 scenario is the 'atmospheric $\mathrm{CO}_{2}$ concentration' (A_co2) (Figure S2), which is significantly correlated to most other model output variables. Most of the variables correlated with 'atmospheric $\mathrm{CO}_{2}$ ' (A_co2) are also significantly correlated to 'surface air temperature' (A_sat), with the exception of 'maximum meridional overturning' (O_motmax), and 'air to land carbon flux '(F_carba2l), which are both significantly correlated to 'surface air temperature' (A_sat) but not to 'atmospheric $\mathrm{CO}_{2}$ ' (A_co2). Furthermore, changes in 'atmospheric $\mathrm{CO}_{2}$ ' (A_co2) are correlated to the changes in 'air to sea carbon flux' (F_carba2o), 'total ocean carbon' (O_totcarb), 'precipitation over ocean' (F_precipO), 'vegetation net primary productivity' (L_vegnpp), 'leaf area index' (L_veglai), 'vegetation carbon' (L_vegcarb), 'the surface upward sensible heat flux' (F_upsens), 'global precipitation' (F_precip) and 'global evaporation' (F_evap).

'Soil respiration' (L_soilresp) is found to be the second indicator for the RCP8.5 scenario. It is significantly correlated to 'surface albedo on land' (A_albsurL), 'terrestrial evapotranspiration' (F_evapL), 'precipitation over land' (F_precipL), 'net surface downward shortwave radiation' (F_dnswr), 'ocean surface heat flux' (F_heat), and 'net top of atmosphere radiation' (F_netrad) (Figure S3). 'Ocean phytoplankton' (O_phyt) was identified as the third indicator for this scenario and is significantly correlated with 'ocean ocean surface nitrate' (O_no3sur) and 'ocean surface phosphate' (O_po4sur). This indicator cluster also occurs for the RCP4.5 scenario. The fourth indicator is 'ocean oxygen' (O_o2), which is significantly correlated to 'ocean surface alkalinity' (O_alksur), again the same cluster is found for the RCP4.5 scenario. As before, there are variables left over. For any assessment these uncorrelated variables, 'air to land carbon flux' (F_carba2l), 'top of atmosphere outgoing longwave radiation' (F_outlwr), 'net upward longwave radiation' (F_uplwr), and 'maximum meridional overturning' (O_motmax), should be included as single indicators. 
Correlations of changes between 2005 and 2100

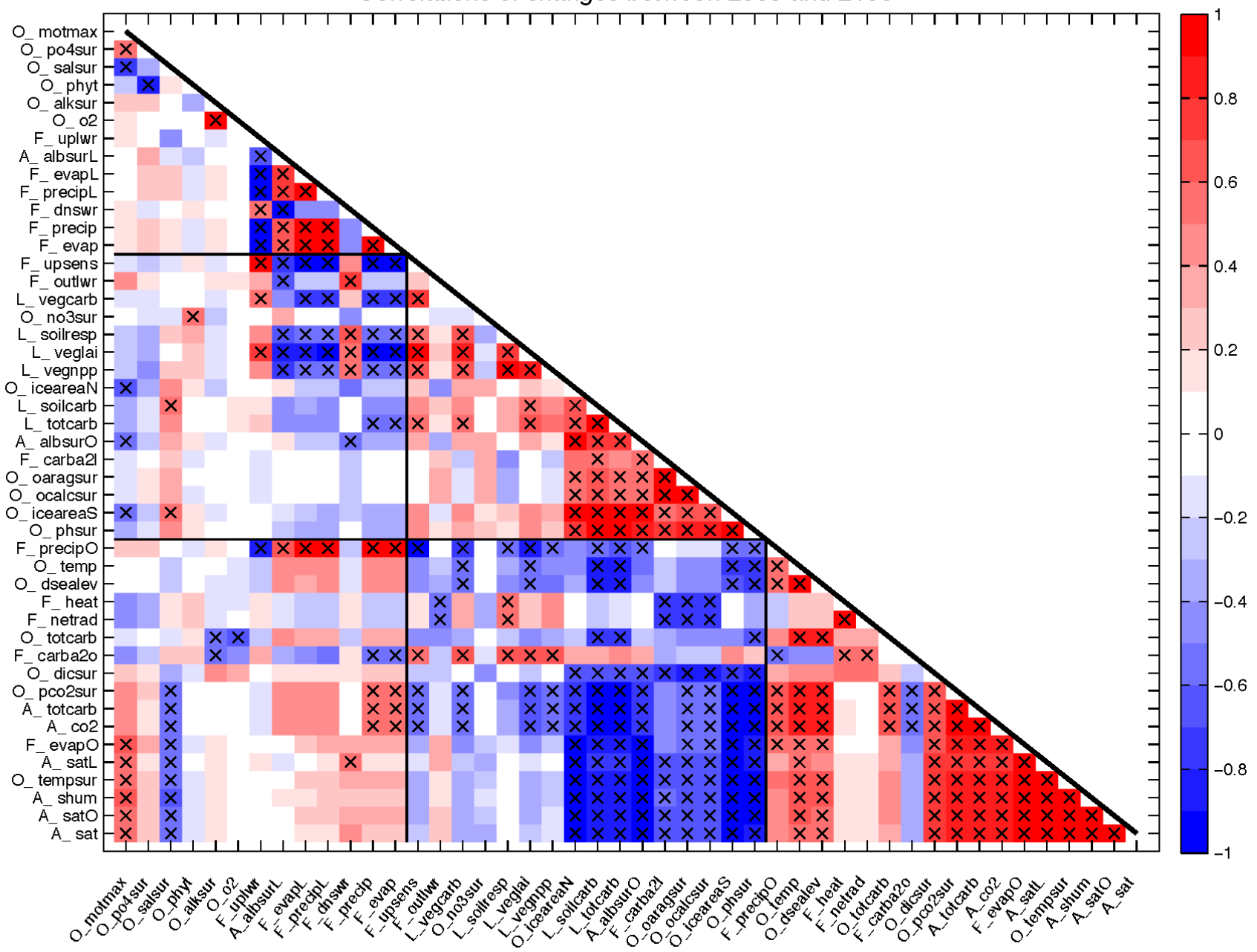

Number of significant correlations for the RCP 8.5 scenario

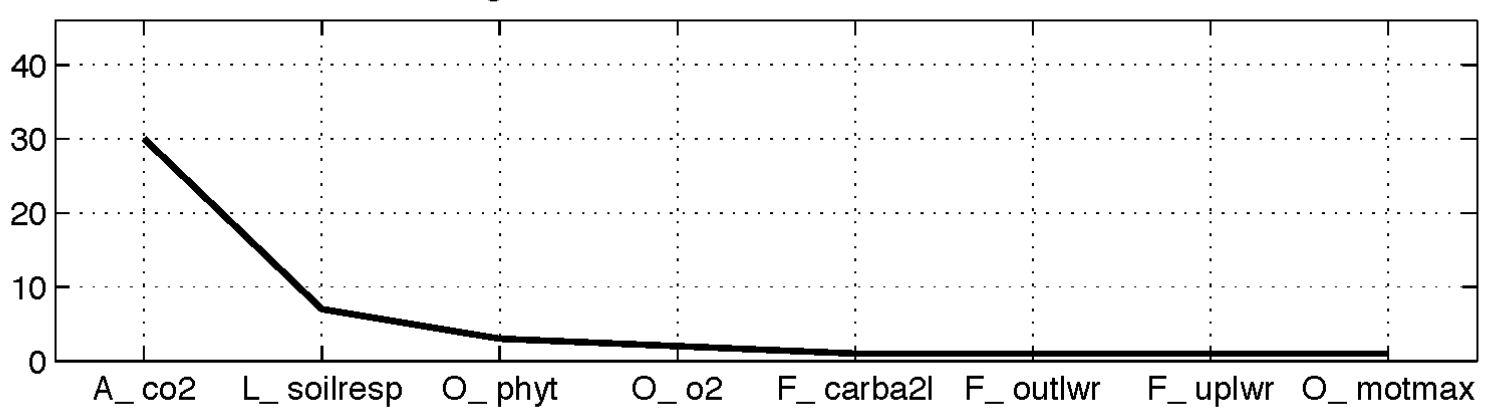

Figure S2. Same as Figure 3 in the main article, for the RCP8.5 scenario. 


\section{What if we prescribe the clusters by scientific meaningful categories?}

To test if we can use knowledge of the Earth system, i.e, expert judgment, to find meaningful clusters in the assessment of the common correlation matrix, which includes the information of all three scenarios, and thereby reduce the amount of needed indicators, we assessed what would happen if the model output variables were clustered into five prescribed categories:

5 temperatures, moisture fluxes, carbon fluxes, carbon reservoirs, and heat fluxes. For this analysis the eight unclustered variables found in the previous analyses (compare section 2.4) remain the same, since they are not significantly correlated to any other variable.
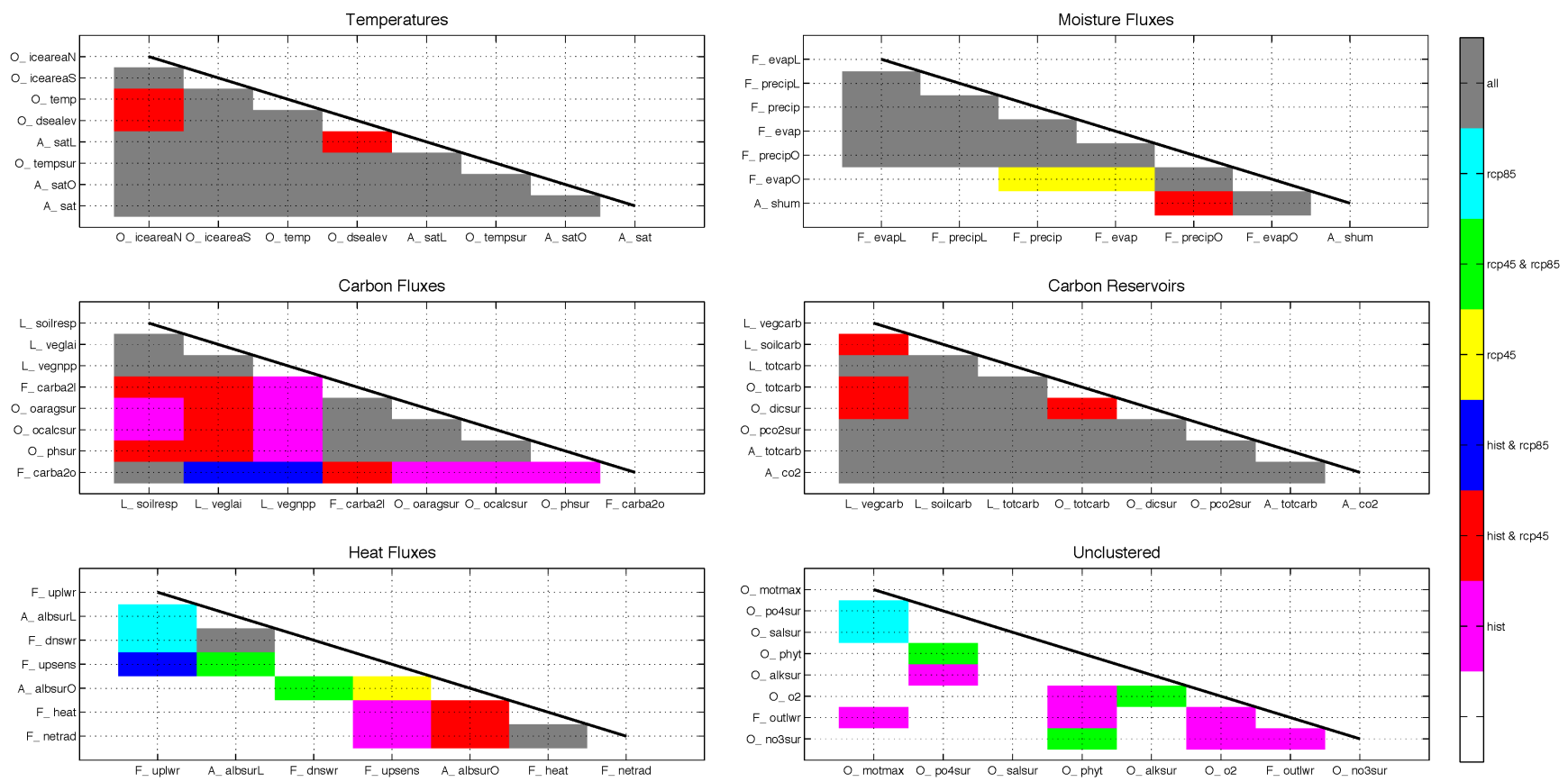

Figure S3. Clusters of the common indicator that are scientifically meaningful to identify indicators from them.

After prescribing the variable clusters (Figure S3), we can study the statistical relationships of the individual variables to each other. For the temperatures cluster we find that almost all the variables are significantly correlated in all the three scenarios. A similar result is found for the carbon reservoirs cluster. Both of these clusters can be represented by choosing one indicator for the clusters, e.g. for the temperatures 'surface air temperature' (A_sat), 'surface air temperature over ocean' (A_satO) or 'sea surface temperature' (O_tempsur) could be used.

For the the clusters describing carbon or moisture fluxes in the Earth system model, the selection of one indicator is more difficult, since often the forcing in one of the scenarios changes the correlation between the variables. For the moisture fluxes, we would need to chose two indicators, namely 'precipitation over ocean' (F_precipO) or 'global evaporation' (F_evap) and 'surface specific humidity' (A_shum). The carbon fluxes cluster also needs two indicators to represent the whole cluster, e.g. 
'soil respiration' (L_soilresp) and 'sea surface pH' (O_phsur). For both these clusters it is mainly the RCP8.5 scenario that changes the significance of the correlations, with only two exceptions: the correlation of 'air to sea carbon flux' (F_carba2o) to 'leaf area index' (L_veglai) and 'vegetation net primary productivity' (L_vegnpp), which changes in the RCP4.5 where the land use forcing is reduced. This again indicates that with increasing atmospheric carbon concentrations or changes in LUC 5 behavior some prevailing relationships in the Earth system might be changed.

The heat fluxes cluster has the most complicated outcome. All combinations of significant correlations between the three scenarios are represented, hinting to the fact that heat fluxes might be very sensitive to changes in the imposed forcing. This results in two indicators that can be found due to clusters of robust correlations across all scenarios, namely 'net top of atmosphere radiation' (F_netrad) and 'net surface downward shortwave radiation' (F_dnswr). But the three remaining heat fluxes are unclustered and would be needed as single indicators. Adding up all the newly found indicators we would end up with 19 indicators, which would be needed for an assessment of the system if clustered by the inclusion of expert judgment. Although this is a higher number of indicators than what was found with the systematic correlation matrix evaluation, it is noteworthy that these indicators now already include some meaningful information about the system.

It could be argued that the expert judgment was made imperfectly, and that with better understanding of the Earth system fewer indicators could be selected. This is undoubtedly true, however these clusters were defined without regarding the correlation matrix in the first place, so they are uninfluenced by the results. This would reflect an expert judgment excluding the learning process from looking at the correlation matrix outcome. It is noteworthy, that by prescribing clusters we lose the opportunity to find previously unknown relationships or correlations between variables. 


\section{How sensitive are the correlation matrices to the single parameter perturbations?}

To describe the SCoMaE method, we assessed the sensitivities of the correlation matrices towards single parameter perturbations, i.e. how strongly a single sensitivity simulation influences the correlation pattern. To do so, we calculate correlations, while leaving out one of the parameter perturbations one at the time. We then look at the standard deviation of the correlations

5 to see how sensitive the correlations are towards single parameter perturbations. If the standard deviation of the correlations is large, we know that the correlation calculation is very sensitive towards single parameter perturbations. In addition we tested the significance of the correlations, marking the cases where more than two thirds of the correlations are significant, even if we leave out one of them at a time.

From this exercise we learn, that some model output variables are very sensitive to the chosen parameter perturbations. The 10 carbon fluxes in the RCP4.5 scenario, for example show a higher sensitivity to to the terrestrial perturbed parameters $\left(\mathrm{CO}_{2}\right.$ fertilization, q10 variations, transpiration sensitivity to $\mathrm{CO}_{2}$ ) than in the other scenarios, since in this forcing scenario natural vegetation is more abundant than in the others. This also explains the high sensitivity of the other land related model output variables, such as 'vegetation NPP' (L_vegnpp), 'leaf area index' (L_veglai), 'soil respiration' (L_soilresp) and 'vegetation carbon' (L_vegcarb), in the RCP4.5 scenario.

15 Naturally, this sensitivity analysis would look different if we had chosen different model parameter for our experiment. The high standard deviations in the historical scenarios for O_po4sur and O_motmax for example are mainly due to the variations in the vertical diffusivity and the temperature sensitivity in marine productivity. 

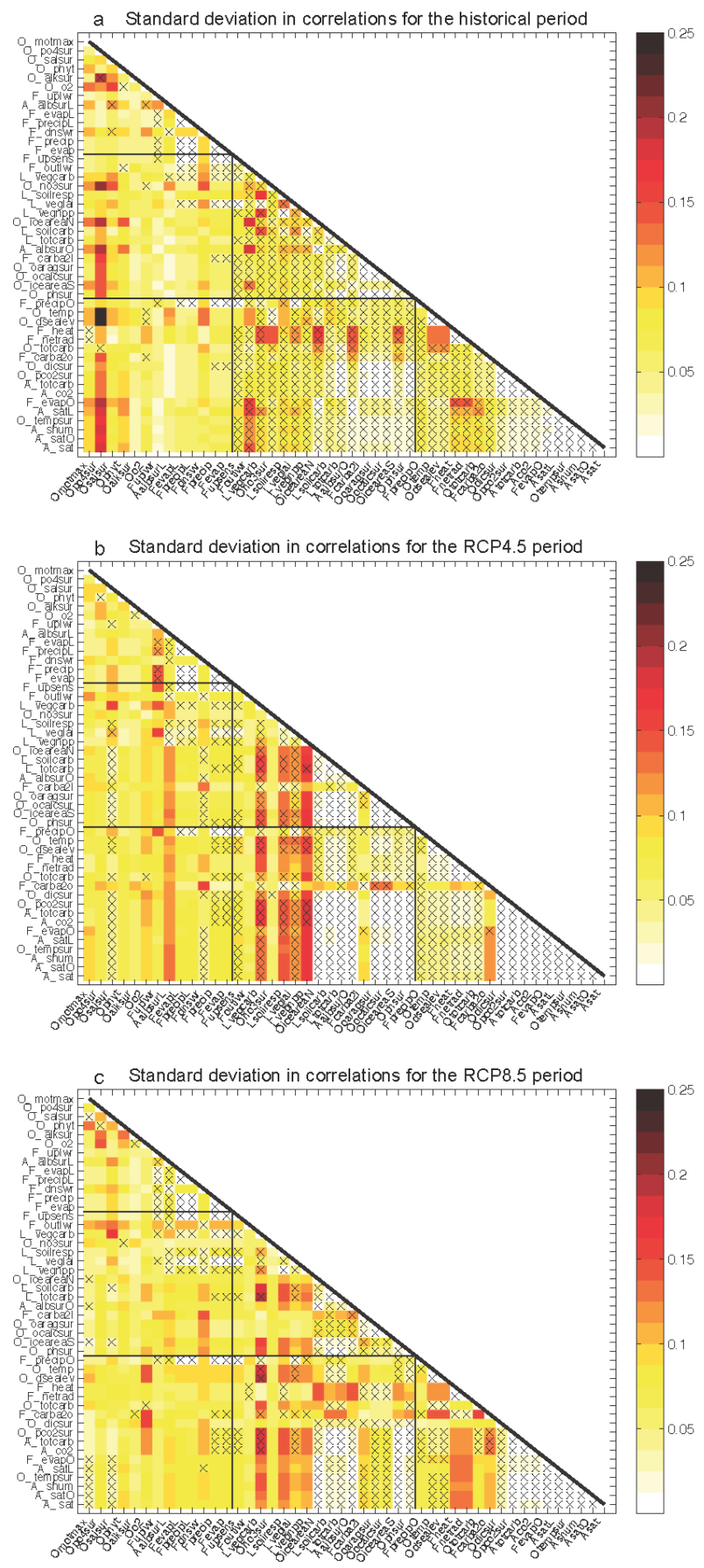

Figure S4. Standard deviations of the correlations in the respective matrix, if one perturbed parameter at a time is left out and the correlation is calculated from the remaining simulations, a) for the historical scenario, b) for the RCP4.5 scenario and c) for the RCP8.5 scenario. 


\section{References}

Eby, M., Weaver, A. J., Alexander, K., Zickfeld, K., Abe-Ouchi, A., Cimatoribus, A. A., Crespin, E., Drijfhout, S. S., Edwards, N. R., Eliseev, A. V., Feulner, G., Fichefet, T., Forest, C. E., Goosse, H., Holden, P. B., Joos, F., Kawamiya, M., Kicklighter, D., Kienert, H., Matsumoto, K., Mokhov, I. I., Monier, E., Olsen, S. M., Pedersen, J. O. P., Perrette, M., Philippon-Berthier, G., Ridgwell, A., Schlosser, A., Schneider Von Deimling, T., Shaffer, G., Smith, R. S., Spahni, R., Sokolov, A. P., Steinacher, M., Tachiiri, K., Tokos, K. S., Yoshimori, M., Zeng, N., and Zhao, F.: Historical and idealized climate model experiments: an intercomparison of Earth system models of intermediate complexity, Climate of the Past, 9, 1111-1140, https://doi.org/10.5194/cp-9-1111-2013, http://www.clim-past.net/9/1111/2013/, 2013.

Le Quere, C., Moriarty, R., Andrew, R. M., Canadell, J. G., Sitch, S., Korsbakken, J. I., Friedlingstein, P., Peters, G. P., Andres, R. J., Boden, T. A., Houghton, R. A., House, J. I., Keeling, R. F., Tans, P., Arneth, A., Bakker, D. C. E., Barbero, L., Bopp, L., Chang, J., Chevallier, F., Chini, L. P., Ciais, P., Fader, M., Feely, R. A., Gkritzalis, T., Harris, I., Hauck, J., Ilyina, T., Jain, A. K., Kato, E., Kitidis, V., Klein Goldewijk, K., Koven, C., Landsch??tzer, P., Lauvset, S. K., Lef??vre, N., Lenton, A., Lima, I. D., Metzl, N., Millero, F., Munro, D. R., Murata, A., S. Nabel, J. E. M., Nakaoka, S., Nojiri, Y., O’Brien, K., Olsen, A., Ono, T., P??rez, F. F., Pfeil, B., Pierrot, D., Poulter, B., Rehder, G., R??denbeck, C., Saito, S., Schuster, U., Schwinger, J., S??f??rian, R., Steinhoff, T., Stocker, B. D., Sutton, A. J., Takahashi, T., Tilbrook, B., Van Der Laan-Luijkx, I. T., Van Der Werf, G. R., Van Heuven, S., Vandemark, D., Viovy, N., Wiltshire, A., Zaehle, S., and Zeng, N.: Global Carbon Budget 2015, Earth System Science Data, 7, 349-396, https://doi.org/10.5194/essd-7-349-2015, 2015.

Thomson, A. M., Calvin, K. V., Smith, S. J., Kyle, G. P., Volke, A., Patel, P., Delgado-Arias, S., Bond-Lamberty, B., Wise, M. A., Clarke, L. E., and Edmonds, J. A.: RCP4.5: a pathway for stabilization of radiative forcing by 2100, Climatic Change, 109, 77, https://doi.org/10.1007/s10584-011-0151-4, http://dx.doi.org/10.1007/s10584-011-0151-4, 2011. 
Table S1. List of globally aggregated model output variables considered in this study. Part 1: Atmosphere and Fluxes

\begin{tabular}{|ccc|}
\hline model output name & description & unit \\
\hline A_albsurL & land surface albedo & {$[1]$} \\
A_albsurO & sea surface albedo & {$[1]$} \\
A_co2 & atmospheric $\mathrm{CO}_{2}$ & {$[\mathrm{ppm}]$} \\
A_sat & air surface temperature & {$\left[{ }^{\circ} \mathrm{C}\right]$} \\
A_satL & land air surface temperature & {$\left[\mathrm{C}^{\circ}\right]$} \\
A_satO & ocean air surface temperature & {$\left[\mathrm{C}^{\circ}\right]$} \\
A_shum & surface specific humidity & {$[1]$} \\
A_totcarb & total atmospheric carbon & {$\left[\mathrm{Pg} \mathrm{C}^{-}\right]$} \\
F_carba21 & air to land carbon flux & {$\left[\mathrm{Pg} \mathrm{C} \mathrm{yr}^{-1}\right]$} \\
F_carba2o & air to sea carbon flux & {$\left[\mathrm{Pg} \mathrm{C} \mathrm{yr}^{-1}\right]$} \\
F_dnswr & net surface downward shortwave radiation & {$\left[\mathrm{W} \mathrm{m}^{-2}\right]$} \\
F_evap & global evaporation & {$\left[\mathrm{kg} \mathrm{H}_{2} \mathrm{O} \mathrm{m}^{-2} \mathrm{~s}^{-1}\right]$} \\
F_evapL & evaporation over land & {$\left[\mathrm{kg} \mathrm{H}_{2} \mathrm{O} \mathrm{m}^{-2} \mathrm{~s}^{-1}\right]$} \\
F_evapO & evaporation over ocean & {$\left[\mathrm{kg} \mathrm{H}_{2} \mathrm{O} \mathrm{m}^{-2} \mathrm{~s}^{-1}\right]$} \\
F_heat & ocean heat flux & {$\left[\mathrm{W} \mathrm{m}^{-2}\right]$} \\
F_netrad & precipitation over ocean \\
F_outlwr & top of atmosphere outgoing longwave radiation & {$\left[\mathrm{W} \mathrm{m}^{-2}\right]$} \\
F_precip & net top of atmosphere radiation & {$\left[\mathrm{W} \mathrm{m}^{-2}\right]$} \\
F_precipL & {$\left[\mathrm{kg} \mathrm{H}_{2} \mathrm{O} \mathrm{m}^{-2} \mathrm{~s}^{-1}\right]$} \\
F_precipO & {$\left[\mathrm{kg} \mathrm{H}_{2} \mathrm{O} \mathrm{m}^{-2} \mathrm{~s}^{-1}\right]$} \\
F_uplwr & {$\left[\mathrm{kg} \mathrm{H}_{2} \mathrm{O} \mathrm{m}^{-2} \mathrm{~s}^{-1}\right]$} \\
F_upsens & {$\left[\mathrm{W} \mathrm{m}^{-2}\right]$} \\
\hline & surface upward sensible heat flux & {$\left[\mathrm{W} \mathrm{m}^{-2}\right]$} \\
\hline
\end{tabular}


Table S2. List of globally aggregated model output variables considered in this study.Part 2: Land and Ocean

\begin{tabular}{|c|c|c|}
\hline model output name & description & unit \\
\hline L_soilcarb & soil carbon & {$[\mathrm{Pg} \mathrm{C}]$} \\
\hline L_soilresp & soil respiration & {$\left[\mathrm{Pg} \mathrm{C} \mathrm{yr}{ }^{-1}\right]$} \\
\hline L_totcarb & total land carbon & {$[\mathrm{Pg} \mathrm{C}]$} \\
\hline L_vegcarb & vegetation carbon & {$[\mathrm{Pg} \mathrm{C}]$} \\
\hline L_veglai & leaf area index & [1] \\
\hline L_vegnpp & vegetation net primary productivity & {$\left[\mathrm{Pg} \mathrm{C} \mathrm{yr}^{-1}\right]$} \\
\hline O_alksur & sea surface alkalinity & {$\left[\mathrm{mol} \mathrm{m}^{-3}\right]$} \\
\hline O_dicsur & sea surface dissolved inorganic carbon & {$\left[\mathrm{mol} \mathrm{m}^{-3}\right]$} \\
\hline O_dsealev & change in sea level & {$[\mathrm{m}]$} \\
\hline O_iceareaN & northern hemisphere sea ice area & {$\left[\mathrm{m}^{2}\right]$} \\
\hline O_iceareaS & southern hemisphere sea ice area & {$\left[\mathrm{m}^{2}\right]$} \\
\hline O_motmax & maximum meridional overturning stream function & {$\left[\mathrm{m}^{3} \mathrm{~s}^{-1}\right]$} \\
\hline O_no3sur & ocean surface nitrate & {$\left[\mathrm{mol} \mathrm{m}^{-3}\right]$} \\
\hline O_o2 & ocean oxygen & {$\left[\mathrm{mol} \mathrm{m}^{-3}\right]$} \\
\hline O_oaragsur & sea surface omega aragonite & {$[1]$} \\
\hline O_ocalcsur & sea surface omega calcite & {$[1]$} \\
\hline O_pco2sur & sea surface partial $\mathrm{CO}_{2}$ pressure & [ppmv] \\
\hline O_phsur & sea surface $\mathrm{pH}$ & {$[1]$} \\
\hline O_phyt & ocean phytoplankton & {$\left[\mathrm{mol} \mathrm{N} \mathrm{m}^{-3}\right]$} \\
\hline O_po4sur & sea surface phosphate & {$\left[\mathrm{mol} \mathrm{m}^{-3}\right]$} \\
\hline O_salsur & sea surface salinity & {$[1]$} \\
\hline O_temp & mean ocean temperature & {$\left[{ }^{\circ} \mathrm{C}\right]$} \\
\hline O_tempsur & sea surface temperature & {$\left[{ }^{\circ} \mathrm{C}\right]$} \\
\hline O_totcarb & total ocean carbon & {$[\mathrm{Pg} \mathrm{C}]$} \\
\hline
\end{tabular}



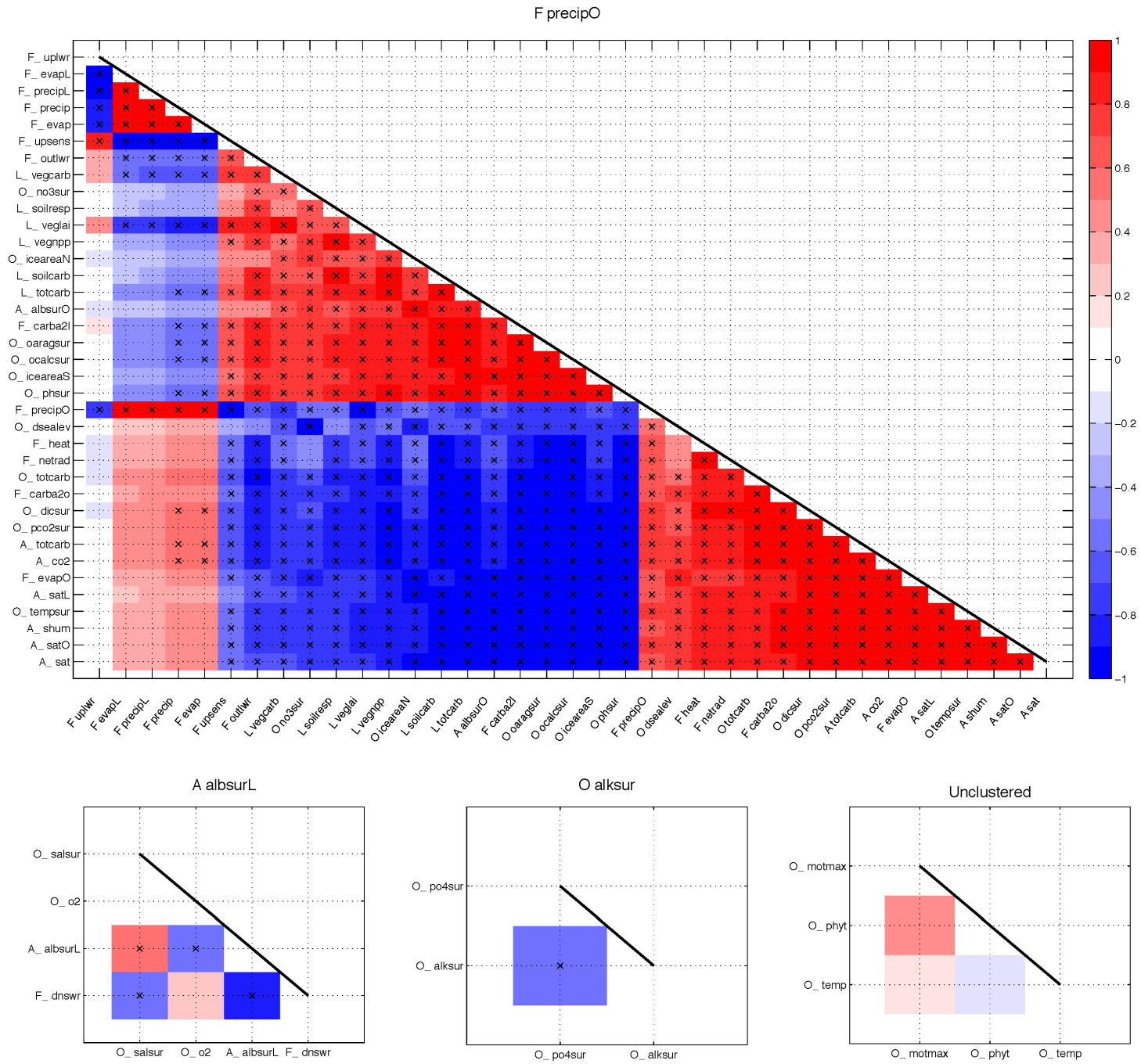

Figure S5. Correlations of the model output variables as clustered under the different headline indicators found for the historical scenario. 

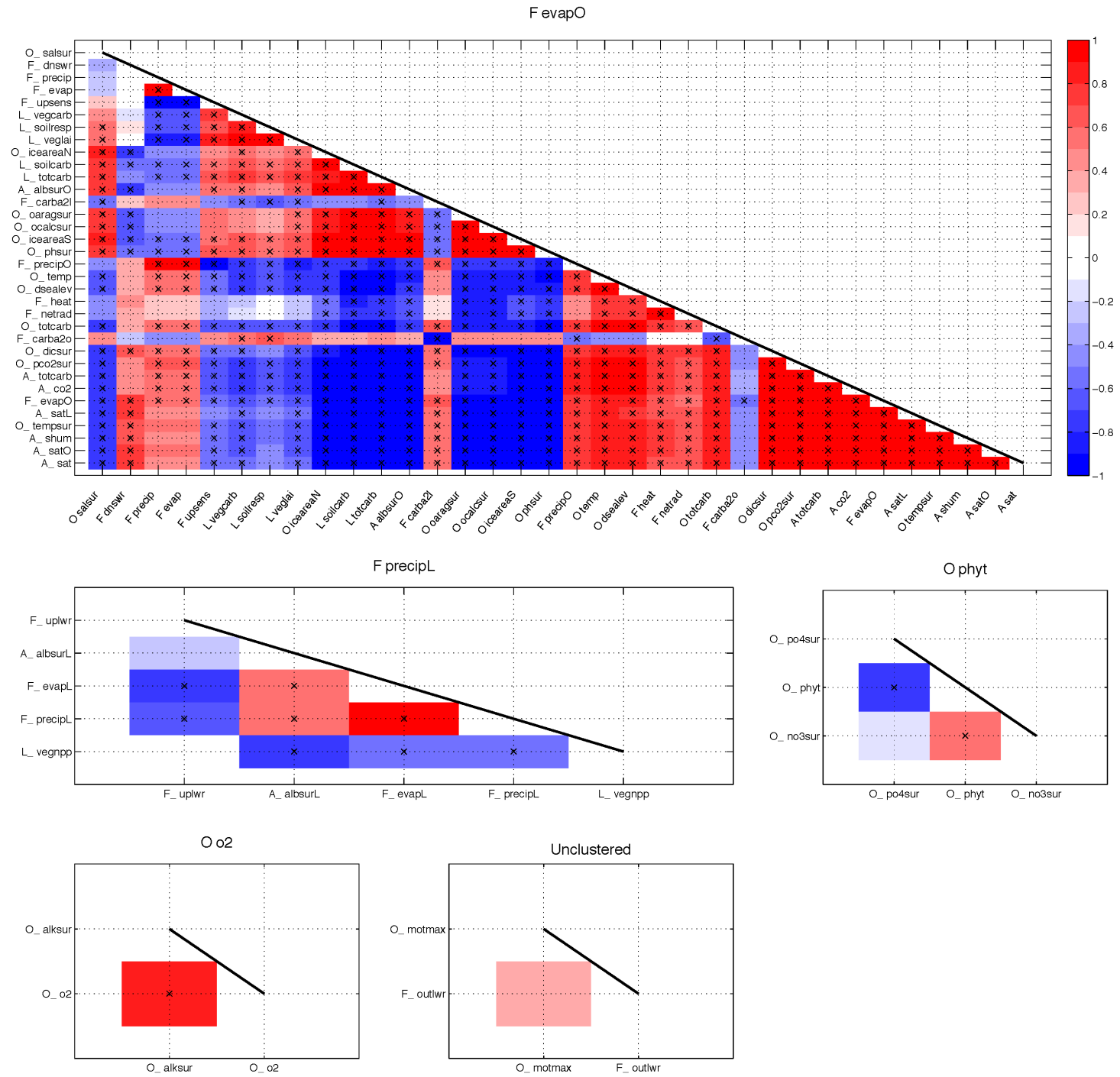

Figure S6. Correlations of the model output variables as clustered under the different headline indicators found for the RCP4.5 scenario. 

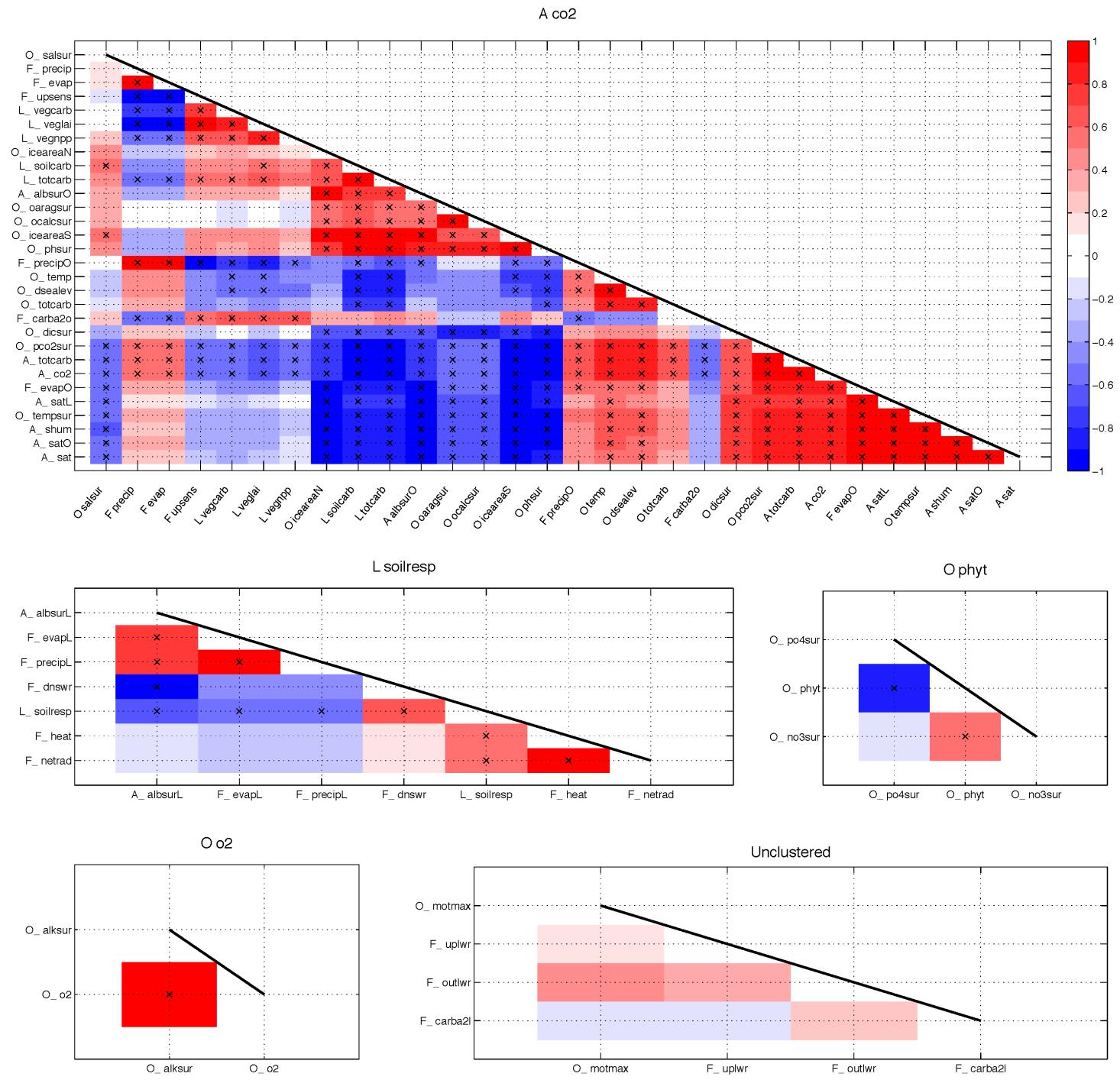

Figure S7. Correlations of the model output variables as clustered under the different headline indicators found for the RCP8.5 scenario. 


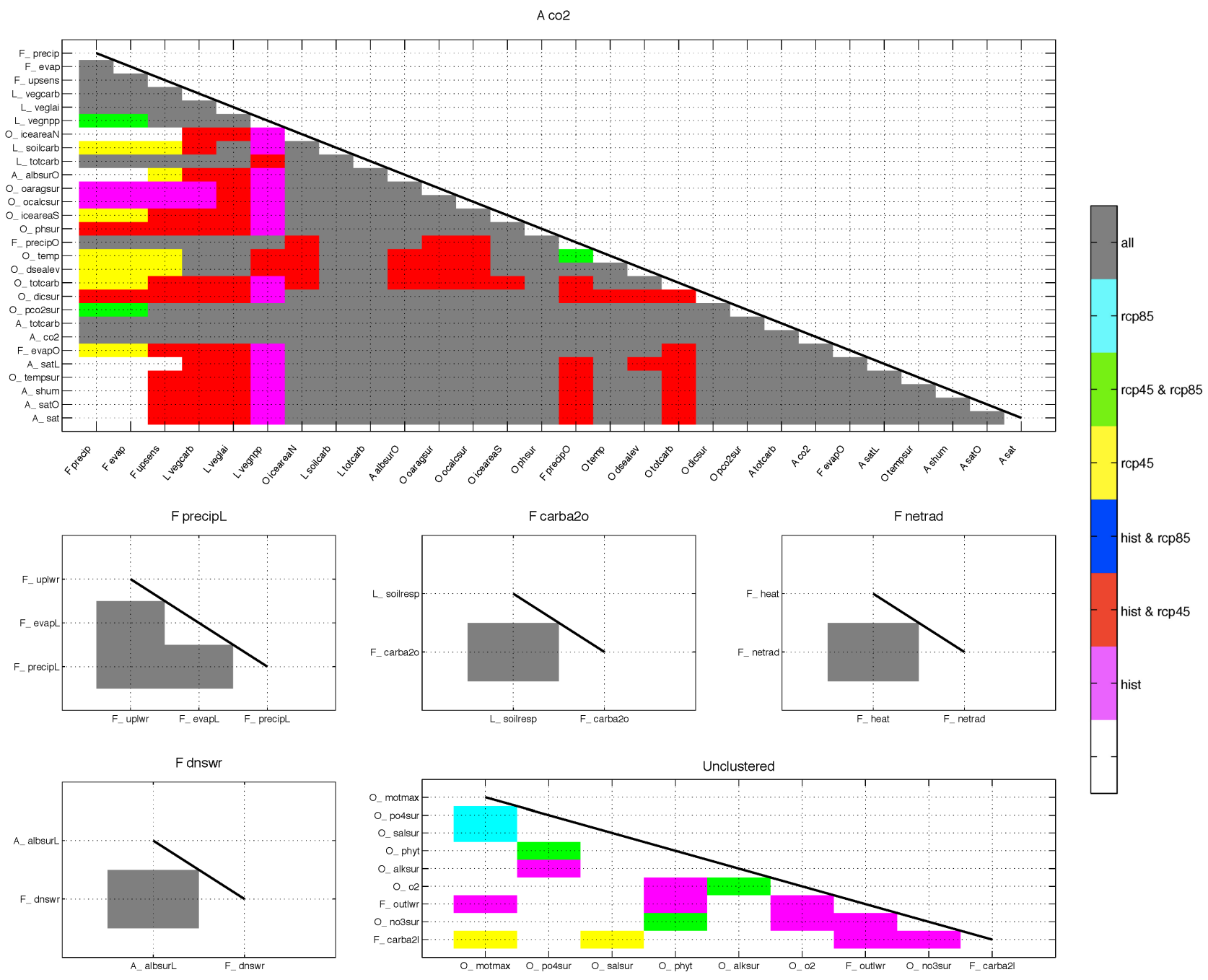

Figure S8. Correlations of the model output variables as clustered under the different headline indicators found for the common indicator. 

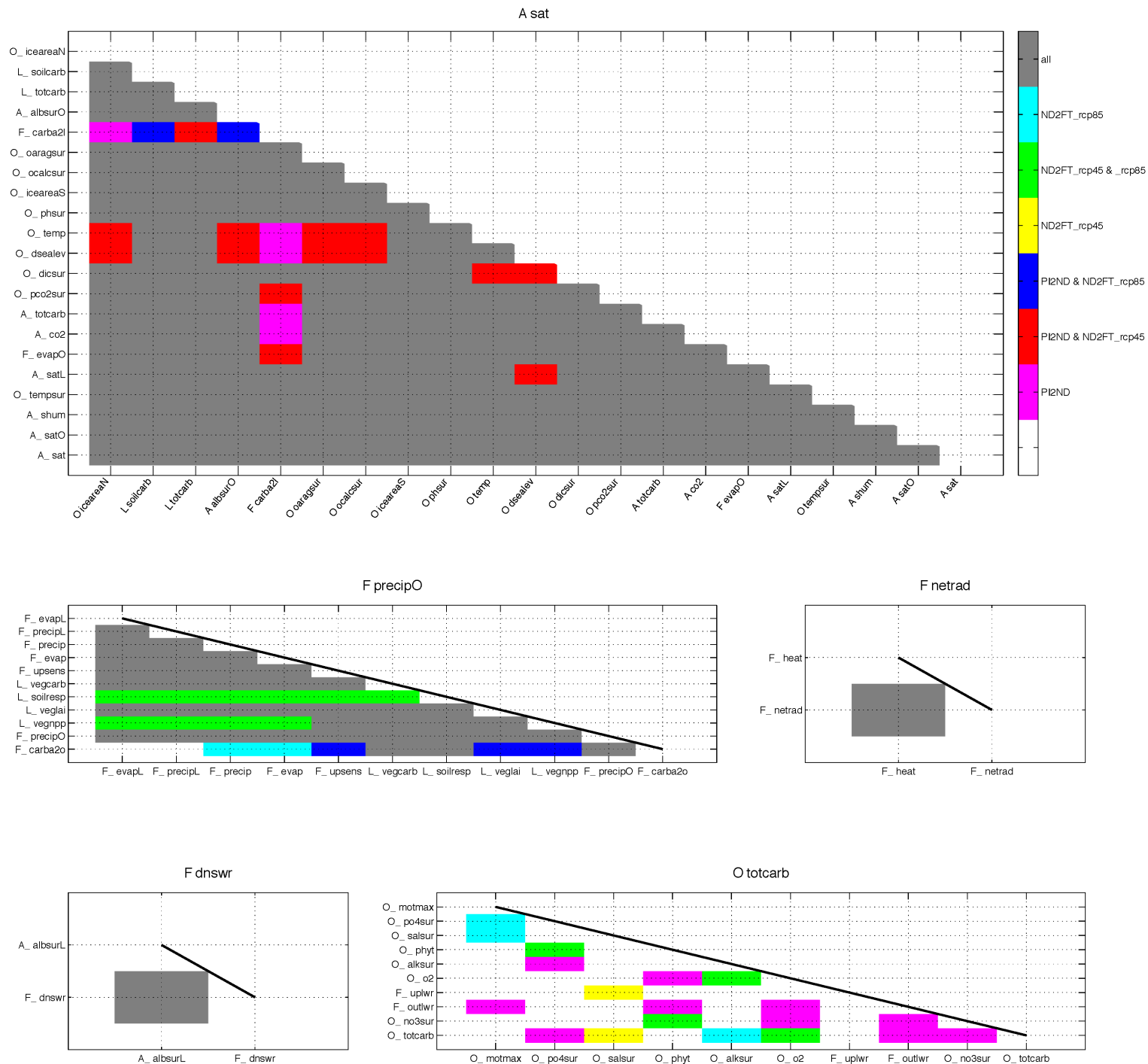

Figure S9. Correlations of the model output variables as clustered under the different headline indicators found for the common indicator, if A_sat is prescribed to be the first headline indicator. 

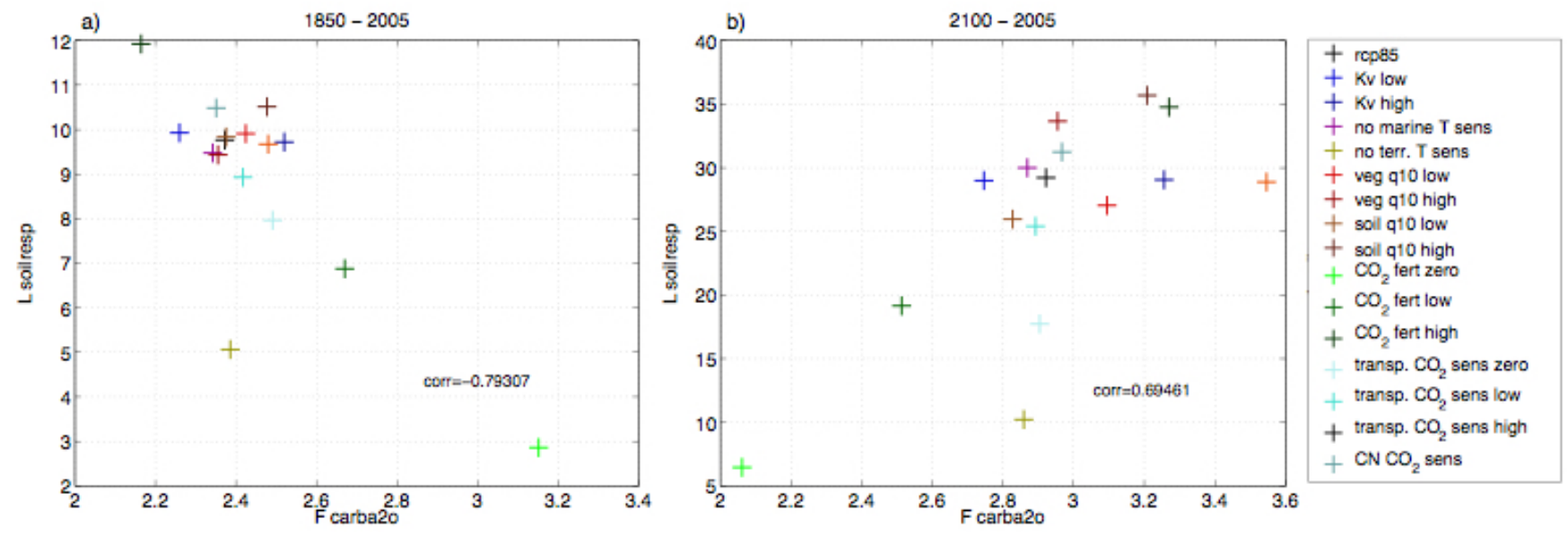

Figure S10. Changes in air to sea carbon flux against changes in soil respiration for a) the historical scenario and b) the RCP8.5 scenario. Colors indicate the respective parameter perturbation simulation, see legend. 